\title{
Effect of Obesity on Soluble Vascular Cell-Adhesion Molecules, Fibrinogen, and von Willebrand Factor Antigen among Obese People in Sapele, Southern Nigeria
}

Kingsley Amaihunwa'

Emmanuel Etim $\mathbb{D}^{2}$

Everista Osime ${ }^{3}$

Zacchaeus Jeremiah ${ }^{4}$

'Department of Medical Laboratory Services, General Hospital Oghara, Oghara City, Delta State, Nigeria; ${ }^{2}$ Department of Hematology and Blood Transfusion Science, Federal Medical Center, Yola, Adamawa State, Nigeria; ${ }^{3}$ Department of Medical Laboratory Science, University of Benin, Benin City, Edo State, Nigeria; ${ }^{4}$ Department of Medical Laboratory Science, Niger Delta University, Yenogoa, Bayelsa State, Nigeria
Correspondence: Emmanuel Etim Laboratory Department, Federal Medical Centre, Yola, Adamawa State, Nigeria Tel +234-806-392-4735

Email emmasuti@yahoo.com
Background/Objective: In obese people, adipose tissue accumulates to the extent of having an adverse effect on certain procoagulant factors, such as: soluble vascular celladhesion molecules (sVCAMs), fibrinogen (Fg), and von Willebrand factor antigen (vWFAg). This study thus aimed to evaluate the impacts of obesity on sVCAMs, Fg, and vWFAg in obese adults in Sapele, southern Nigeria.

Methods: A total of 312 obese adults and 103 controls aged 18-65 years were enrolled for this study. Venous blood $(4.5 \mathrm{~mL})$ was collected into EDTA containers for measurement of Fg, vWFAg, and sVCAMs using ELISA method. Data were analyzed using Student's $t$-test, correlations, and one-way ANOVA followed by least significant difference post hoc tests on Microsoft Excel 2010 and SPSS 21.0, and results were expressed as means \pm SD.

Results: Mean body-mass index of obese and control (non-obese) subjects was $36.82 \pm 0.55$ $\mathrm{kg} / \mathrm{m}^{2}$ and $20.43 \pm 0.29 \mathrm{~kg} / \mathrm{m}^{2}$ respectively $(P<0.001)$. Mean $\mathrm{Fg}$ in obese subjects was 78.45 $\pm 13.79 \mathrm{ng} / \mathrm{ml}$ and in the control group $40.00 \pm 2.55 \mathrm{ng} / \mathrm{ml}$. Mean vWFAg in obese subjects was $85.63 \pm 7.00 \mathrm{u} / 1$ and in control subjects $59.02 \pm 2.48 \mathrm{u} / 1$. Mean sVCAM counts in obese and control subjects were $7.53 \pm 0.96 \mathrm{Iu} / 1$ and $4.16 \pm 0.19 \mathrm{u} / 1$, respectively $(P<0.01)$.

Conclusion: Fg, vWFAg, and sVCAM levels were higher in obese people than the nonobese.

Keywords: obesity, sVCAM, vWFAg, fibrinogen, Sapele

\section{Introduction}

Obesity is a medical condition in which excess body fat has accumulated to a level that produces adverse effects on health. ${ }^{1}$ A person is said to be obese when the body-mass index (BMI) is $>30$. Obesity has emerged as a global health problem and one of the leading avoidable causes of mortality worldwide. ${ }^{2}$ In the past obesity was considered an indication of good health, as well as wealth and prosperity, until Hippocrates realized that obesity leads to infertility and early mortality. ${ }^{3}$

In addition, uncontrolled body weight gain is associated with many chronic conditions, such as: cardiovascular diseases, type 2 diabetes mellitus, asthma, obstructive sleep apnea, cancer, and bone diseases. There is a rising trend of overweight and obesity in developed and developing countries worldwide, resulting in increased business costs, low productivity, and poor health. ${ }^{1}$ Strong positive correlations have been observed between physical activity and weight gain in 
multiple cross-sectional studies. ${ }^{4}$ It has been established that this relationship is bidirectional in nature i.e obesity discourages one from undertaking physical activity, while inactivity promotes excessive weight gain that leads to obesity, resulting in both cardiovascular and diabetic risk in individuals, in addition to enhancing the severity of other risk factors.

In obesity, there is a chronic inflammatory state characterized by excess adipose-tissue deposition on endocrine organs that is linked to a buildup of adipocytokines, such as: inflammatory mediators and metabolic regulators. This resultant inflammatory state usually gives rise to upregulated alteration of certain mechanisms, leading to activation of procoagulant factors, which results in increased risk of thrombosis. ${ }^{5}$ Chronic diseases associated with obesity usually result from complicated interphases of genetics and ecosystems that alter levels of procoagulant factors such as: soluble vascular cell-adhesion molecules (sVCAMs), fibrinogen $(\mathrm{Fg})$, and von Willebrand factor (vWF), resulting in hypercoagulability, hypofibrinolysis, or both. Therefore, it is imperative to analyze the effect of obesity on these procoagulant factors, and this was the impetus for this study. The prevalence of obesity in Nigeria is relatively high: $8.1 \%-22.2 \%$. In addition, relationships between obesity and sVCAMs, vWF, and Fg alterations have not been well documented in southern Nigeria in general and Sapele in particular. We therefore aimed to evaluate the effects of obesity on these procoagulants in obese adults in Sapele and its environs in order to provide evidencebase strategies for better management of patients with obesity in this locality. Sapele is a city located in central part of Delta State, southern Nigeria. Its population is 174,273 (2006 figure), and it accommodates a number of tribes such as: Okpe, Urhobo, Itsekiri, Ibo, Ijaw, Isoko, Hausa, Edo, Yoruba, Ibibio, Nupe, Tiv, and Fulani. Common food consumed in this area is starch, yam, garri, rice, beans, plantain, palm oil, fish, meat, and periwinkle.

vWF is a large multimeric glycoprotein produced constitutively as ultralarge endothelium megakaryocytes, while sVCAMs are cell surface-binding proteins and major biomarkers of inflammatory processes, which are a common episodes in obesity. It is believed that, providing information on the effects of obesity on the afortementioned procoagulants will help in the formulation of appropriate strategies and programs for maximum health benefit to people with obesity in Sapele and indeed Nigeria at large.

\section{Inclusion Criteria}

People whose BMI was $>30$, aged 18-65 years, and residing in Sapele and its environs were recruited.

\section{Exclusion Criteria}

People whose BMI was $<30$, pregnant women, those with hypertension, demonstrable ascites, intra-abdominal masses, malignancy, renal disease, liver disease, diabetes mellitus, and HIV infection, and those currently on oral anticoagulants, had undergone recent surgery ( $<3$ months), and who refused consent were excluded.

\section{Methods}

This was a cross-sectional study carried out at Central Hospital, Sapele, General Hospital, Oghara and Biomed Diagnostic Centre, Sapele. A total of 415 subjects were enrolled. These comprised 312 obese subjects $(111$ men and 201 women) and 103 non-obese subjects (40 men and 63 women) used as controls.

\section{Calculation of Sample Size}

The sample size was calculated using the formula:

$$
\mathrm{N}=\frac{\mathrm{Z}^{2} \mathrm{pq}}{\mathrm{d}^{2}}
$$

where $\mathrm{Z}=1.96, \mathrm{P}=14 \%$ (prevalence in Nigeria according to Siminialayi et al in 2008), $d=$ degree of accuracy (set at 0.05 ), and $\mathrm{q}=1-\mathrm{P}=1-0.14=0.86$ :

$$
\begin{gathered}
\mathrm{N}=\frac{(1.96)^{2} \times 0.14 \times 0.86}{(0.05)^{2}} \\
\mathrm{~N}=\frac{3.84 \times 0.14 \times 0.86}{0.0025} \\
\mathrm{~N}=\frac{0.462}{0.0025}
\end{gathered}
$$

The minimum sample size calculated was 185 , which was later expanded to 312 to improve precision.

\section{Sample Collection}

Venous blood $(4.5 \mathrm{~mL})$ was collected from all participants into EDTA containers. Samples were analyzed within 1 hour of collection using ELISA method. 


\section{Ethics}

Ethics approval for this study was obtained from the ethics committee of Central Hospital, Sapele Medical Zone, Sapele on December 8, 2016 (reference SNZ/A.31VOL.3/54). Informed consent was obtained from all subjects, as well as a completed structured questionnaire. The study was conducted in accordance with the Declaration of Helsinki.

\section{Sample Analysis}

Samples were further allowed to stand and then were centrifuged at 3,000 rpm for 10 minutes to obtain clear plasma, which was kept at $-20^{\circ} \mathrm{C}$ until analysis. ELISA kits used were from Sunglong Biotech, Hangzhou, China (SLO708hu, SL1839Hu, and SL1626Hu).

\section{vWFAg Assay}

Standard solution and sample (100 $\mu \mathrm{L}$ each) were added to each well and the blanks left empty and incubated for 90 minutes at $37^{\circ} \mathrm{C}$. The solution was removed, $100 \mu \mathrm{L}$ biotinylated detection antibody added to it, and incubated for 60 minutes at $37^{\circ} \mathrm{C}$. The solution was then aspirated, the wells washed thrice, and $100 \mu \mathrm{L}$ HRP conjugate was added and left for 30 minutes at $37^{\circ} \mathrm{C}$, after which the solution was aspirated and washed five times. Substrate reagent $(90 \mu \mathrm{L})$ was added and incubated for 15 minutes at $37^{\circ} \mathrm{C}$, then $50 \mu \mathrm{L}$ stop solution was added. The optical density (OD) of the blank well was set at zero. The absorbance OD of each well was read at $450 \mathrm{~nm}$ using a microplate reader. OD values were proportional to the concentration of the measured parameters.

\section{sVCAM Assay}

Standard solution and sample (100 $\mu \mathrm{L}$ each) were added to each well and the blank left empty and incubated for 90 minutes at $37^{\circ} \mathrm{C}$. The solution was removed and $100 \mu \mathrm{L}$ biotinylated detection antibody added, then incubated for 60 minutes at $37^{\circ} \mathrm{C}$. The solution was aspirated and the wells washed thrice, then $100 \mu \mathrm{L}$ HRP conjugate was added and incubated for 30 minutes at $37^{\circ} \mathrm{C}$. The solution was aspirated and washed five times. Substrate reagent $(90 \mu \mathrm{L})$ was added and incubated for 15 minutes at $37^{\circ} \mathrm{C}$, then $50 \mu \mathrm{L}$ stop solution was added. The OD of the blank well was set at zero. The absorbance OD of each well was read at $450 \mathrm{~nm}$ using a microplate reader. OD values were proportional to the concentration of the measured parameters.

\section{Fibrinogen Assay}

Standard solution and sample (100 $\mu \mathrm{L}$ each) were added to each well and the blank left empty and incubated for 90 minutes at $37^{\circ} \mathrm{C}$. The solution was removed and $100 \mu \mathrm{L}$ biotinylated detection antibody added, then incubated for 60 minutes at $37^{\circ} \mathrm{C}$. The solution was aspirated and the wells washed thrice, then $100 \mu \mathrm{L}$ HRP conjugate was added and incubated for 30 minutes at $37^{\circ} \mathrm{C}$. The solution was aspirated and washed five times. Substrate reagent (90 $\mu \mathrm{L}$ ) was added and incubated for 15 minutes at $37^{\circ} \mathrm{C}$, then $50 \mu \mathrm{L}$ stop solution was added. The OD of the blank well was set at zero. The absorbance OD of each well was read at $450 \mathrm{~nm}$ using a microplate reader. OD values were proportional to the concentration of the measured parameters.

\section{Body-Mass Index}

BMI categories were defined using the WHO 2005 criteria: normal weight $18.5-<25 \mathrm{~kg} / \mathrm{m}^{2}$, overweight $25-<30$ $\mathrm{kg} / \mathrm{m}^{2}$, and obese $\geq 30 \mathrm{~kg} / \mathrm{m}^{2}$. Values for anthropometric variables are shown in Table 1.

Table I Anthropometric variables of obese and normal-weight subjects

\begin{tabular}{|c|c|c|c|c|}
\hline & $\begin{array}{l}\text { Obese }(n=3 \mid 2), \\
\text { mean } \pm \text { SEM }\end{array}$ & $\begin{array}{l}\text { Normal }(n=103) \text {, } \\
\text { mean } \pm \text { SEM }\end{array}$ & $t$ & $P$ \\
\hline Age (years) & $38.95 \pm 0.85$ & $26.75 \pm 0.84$ & 9.538 & $0 * *$ \\
\hline SBP $(\mathrm{mmHg})$ & $|25| 8 \pm.|.3|$ & || $4.4 \mid \pm 1.20$ & 5.564 & $0 * *$ \\
\hline DBP $(\mathrm{mmHg})$ & $77.55 \pm 0.79$ & $69.53 \pm 0.92$ & 6.398 & $0 * *$ \\
\hline Weight (kg) & $101.69 \pm 1.55$ & $56.53 \pm 0.92$ & 21.114 & $0 * *$ \\
\hline Height (m) & $1.66 \pm 0.01$ & $1.66 \pm 0.01$ & -0.056 & $0.956^{\dagger}$ \\
\hline BMI $\left(\mathrm{kg} / \mathrm{m}^{2}\right)$ & $36.82 \pm 0.55$ & $20.43 \pm 0.29$ & 21.913 & $0 * *$ \\
\hline WC (Inch) & $45.74 \pm 0.46$ & $29.59 \pm 0.31$ & 25.181 & $0 * *$ \\
\hline HC (Inch) & $49.56 \pm 0.48$ & $33.37 \pm 0.53$ & 21.644 & $0 * *$ \\
\hline WHR & $0.92 \pm 0.01$ & $0.90 \pm 0.01$ & 2.827 & $0.005^{* *}$ \\
\hline $\mathrm{WHtR}(\operatorname{lnch} / \mathrm{m})$ & $27.56 \pm 0.30$ & $17.83 \pm 0.22$ & 23.159 & $0 * *$ \\
\hline
\end{tabular}

Notes: ${ }^{* * P}<0.01 ; * P<0.05 ;{ }^{\dagger}$ not significant.

Abbreviations: WHtR, waist:height ratio; WHR, waist:hip ratio; HC, hip circumference; WC, waist circumference. 


\section{Data Analysis}

Data analysis was done using Microsoft Excel 2010 and SPSS 21.0. Results were expressed as means \pm SD. We used Student's $t$-test, correlations and one-way ANOVA for analysis, followed by least significant difference post hoc tests for the obese. Correlations between variables were assessed using Pearson's linear regression analysis. Statistical significance was set at $P<0.05$.

\section{Results}

Obese subjects had significantly higher Fg $(P<0.05)$, vWFAg $(P<0.01)$, and sVCM $(P<0.01)$ levels than normal-weight subjects, as shown in Table 2.

Fg, vWFAg, and sVCAM levels in obese subjects were significantly higher in those aged 20-29 and 30-39 years $(P<0.05)$ than controls, with no significant difference between those aged $>40$ years and controls, as shown in Table 3 . procoagulant factors in obese male and female subjects, showed no significant difference in Fg, vWFAg, or sVCAMs $(P>0.05)$ as shown in Table 4 below.

Table 5 shows the levels of Fg, vWFAg, and sVCAMs in obese and non-obese women. There were no significant differences in Fg or sVCAMs, but vWFAg was higher in obese women than non-obese women.

\section{Discussion}

This study focused on the effect of obesity on Fg, sVCAM, and vWFAg levels in obese adults in Sapele and its environs. Obese subjects had significantly higher Fg levels than normal-weight subjects. This implies that excessive weight gain contributes to increased concentration of plasma $\mathrm{Fg}$, in accordance with Davalo and Akassoglou. ${ }^{6} \mathrm{Fg}$ is a positive acute-phase protein, and its blood level rises in response to systemic inflammation and endothelial damage. Elevated Fg in inflammation has been found to be associated with thrombosis and vascular injury. ${ }^{7}$

Table $2 \mathrm{Fg}$, vWF, and sVCAM levels in obese and normal-weight subjects

\begin{tabular}{|l|l|l|l|l|}
\hline & Obese $(\mathbf{n}=\mathbf{3}$ I 2) & Normal $(\mathbf{n}=\mathbf{1 0 3})$ & $\mathbf{t}$ & $\mathbf{P}$ \\
\hline Fg (ng/ml) & $78.45 \pm 13.79$ & $40.00 \pm 2.55$ & 2.136 & $0.034^{*}$ \\
vWFAg (u/l) & $85.63 \pm 7.00$ & $59.02 \pm 2.48$ & 2.868 & $0.005^{* *}$ \\
sVCAMs (u/l) & $7.53 \pm 0.96$ & $4.16 \pm 0.19$ & 2.697 & $0.008^{* *}$ \\
\hline
\end{tabular}

Notes: $* * P<0.01 ; * P<0.05$.

Table $3 \mathrm{Fg}$, vWF, and sVCAM levels in obese and control subjects aged 20-29, 30-39, 40-49, and $\geq 50$ years

\begin{tabular}{|c|c|c|c|c|}
\hline & Obese $(n=3 \mid 2)$, Mean $\pm m S E M$ & Controls $(n=103)$, mean \pm mSEM & $\boldsymbol{t}$ & $P$ \\
\hline 20-29 years & $\mathrm{n}=75$ & $n=22$ & & \\
\hline $\mathrm{Fg}(\mathrm{ng} / \mathrm{ml})$ & $100.59 \pm 209.23$ & $37.01 \pm 15.02$ & 3.084 & $0.002 * *$ \\
\hline vWFAG (u/l) & $74.59 \pm 55.32$ & $58.12 \pm 17.87$ & 2.839 & $0.005^{* *}$ \\
\hline sVCAMs $(u / l)$ & $8.23 \pm|2.6|$ & $4.07 \pm 1.40$ & 3.338 & $0.001 * *$ \\
\hline $30-39$ years & $n=99$ & $n=33$ & & \\
\hline $\mathrm{Fg}(\mathrm{ng} / \mathrm{ml})$ & $99.44 \pm 209.23$ & $36.01 \pm 15.02$ & 3.085 & $0.002 * *$ \\
\hline vWFAG (ul) & $73.59 \pm 55.32$ & $57.12 \pm 17.87$ & 2.739 & $0.005^{* *}$ \\
\hline sVCAMs $(\mathrm{u} / \mathrm{l})$ & $8.24 \pm|2.6|$ & $4.08 \pm 1.40$ & 3.348 & $0.001 * *$ \\
\hline $40-49$ years & $\mathrm{n}=90$ & $\mathrm{n}=30$ & & \\
\hline $\mathrm{Fg}(\mathrm{ng} / \mathrm{ml})$ & $71.14 \pm 64.24$ & $68.80 \pm 34.51$ & 0.113 & 0.910 \\
\hline vWFAG (u/l) & $93.79 \pm 79.09$ & $72.10 \pm 26.66$ & 0.860 & 0.392 \\
\hline sVCAMs (u/l) & $7.69 \pm 7.63$ & $5.24 \pm 1.35$ & 1.010 & 0.315 \\
\hline $50-59$ years & $n=48$ & $n=18$ & & \\
\hline $\mathrm{Fg}(\mathrm{ng} / \mathrm{ml})$ & $41.83 \pm 15.63$ & $30.75 \pm 0.87$ & 1.396 & 0.174 \\
\hline vWFAG (u/l) & $84.88 \pm 58.96$ & $40.50 \pm 0.58$ & 1.482 & 0.150 \\
\hline sVCAMs $(\mathrm{u} / \mathrm{l})$ & $4.42 \pm 1.17$ & $3.25 \pm 0.29$ & 1.956 & 0.061 \\
\hline
\end{tabular}

Notes: $* * P<0.01 ; * P<0.05$. 
Table $4 \mathrm{Fg}$, vWFAg, and sVCAM levels in obese male and female subjects

\begin{tabular}{|l|l|l|l|l|}
\hline & Men (n=III) & Women $(\mathbf{n}=201)$ & $t$ & $P$ \\
\hline Fg (ng/ ml) & $46.82 \pm 5.83$ & $68.69 \pm 12.83$ & -0.813 & $0.418^{\dagger}$ \\
vWFAg (u/l) & $77.84 \pm 16.31$ & $80.32 \pm 6.82$ & -0.153 & $0.879^{\dagger}$ \\
sVCAMs (u/l) & $5.84 \pm 1.06$ & $6.60 \pm 0.92$ & -0.384 & $0.702^{\dagger}$ \\
\hline
\end{tabular}

Notes: $* * P<0.01 ; P<0.05 ;{ }^{\dagger}$ not significant.

Table $5 \mathrm{Fg}$, vWFAg, and sVCAM levels in obese and normal-weight female subjects

\begin{tabular}{|c|c|c|c|c|}
\hline & Obese $(n=201)$, mean \pm SEM & Normal $(n=78)$, mean \pm SEM & $t$ & $\boldsymbol{P}$ \\
\hline $\mathrm{Fg}(\mathrm{ng} \mathrm{ml})$ & $69.11 \pm 12.98$ & $41.46 \pm 3.48$ & 1.481 & $0.141^{\dagger}$ \\
\hline vWFAg (u/l) & $79.83 \pm 6.88$ & $57.55 \pm 2.75$ & 2.226 & $0.028 *$ \\
\hline $\operatorname{sVCAMs}(\mathrm{m} / \mathrm{l})$ & $6.64 \pm 0.93$ & $4.27 \pm 0.24$ & 1.773 & $0.079^{\dagger}$ \\
\hline
\end{tabular}

Notes: $* * P<0.01 ; * P<0.05 ;{ }^{\dagger}$ not significant.

Obese subjects had significantly higher vWFAg levels than normal-weight subjects. This implies that weight gain increases plasma vWFAg and that this is also an induced response to systemic inflammation and tissue injury in obesity, in accordance with Randi and Laffan. ${ }^{8}$ Nevertheless, studies carried out in mice have revealed that increased inflammatory cytokines may induce depletion of antioxidant stores, upregulation of adhesion molecules on lung endothelia, and greater susceptibility of endothelia to injury, resulting in elevated vWFAg, ${ }^{9}$ in agreement with the results of this study and that of Guo et al. ${ }^{10}$

Obese subjects also had significantly higher levels of sVCAMs than normal-weight subjects. This implies that excessive weight gain increases plasma sVCAM levels, which is in consistent with earlier report by Porreca et al. ${ }^{11}$ This present study further observed that, obesity is involved with increased levels of sVCAMs, an atherosclerotic marker and essential pointer toward inflammatory processes involving activation of endothelial tissue, indicating endothelial damage and increased risk of thrombosis in obese subjects. Nevertheless, there was no significant difference in levels of Fg, sVCAMs, or vWFAg between the sexes in this study, the reason for which is unclear.

\section{Conclusion}

This study observed that there were significantly higher levels of Fg, sVCAMs, and vWFAg among obese people $(P<0.01)$ than non-obese individuals in Sapele, southern Nigeria.

\section{Disclaimer}

The views expressed in this article are those of the authors, not an official position of any hospital or institution.

\section{Financial Sponsorship}

This study was not sponsored, and the equipment used was provided by the hospital in which this work was done.

\section{Disclosure}

The authors report no conflicts of interest regarding this work.

\section{References}

1. World Health Organization. Health effects of overweight and obesity in 195 countries over 25 years - obesity calibrator. Eng $J$ Med. 2015;377(1):13-27.

2. Barness LA, Opitz JM, Gilbert E. Obesity: genetic, molecular and environmental aspects. Am J Med Genet. 2007;143(24):3016-3034. doi:10.1002/ajmg.a.32035

3. Haslam DW, James WP. Obesity. Lancet. 2005;366(9492):11971209. doi:10.1016/S0140-6736(05)67483-1

4. Lau DC, Douketis JD, Morrison KM, Hramiak IM, Sharma AM, Ur E. Canadian clinical practice guidelines on the management and prevention of obesity in adults and children summary. Canadian Med Annu J. 2007;176(8):1-13.

5. Faber DR, De Groot PG, Visseren FL. Role of adipose tissue in haemostasis, coagulation and fibrinolysis. Obesity Rev. 2009;10 (5):554-563.

6. Davalos D, Akassoglou K. Fibrinogen as a key regulator of inflammation in disease. Semin Immunopathol. 2012;34(1):43-62. doi:10.1007/s00281-011-0290-8

7. Repetto O, De Re V. Coagulation and fibrinolysis in gastric cancer. Ann N Y Acad Sci. 2017;10:1111-13454.

8. Randi AM, Laffan MA. Von Willebrand factor and angiogenesis: basic and applied issue. $J$ Thrombosis Haemostasis. 2017;15(1):1320. doi:10.1111/jth.13551

9. Klein CL, Hoke TS, Fang WF, Altmann CJ, Douglas IS, Faubel S Interleukin-6 mediates lung injury following ischemic acute kidney injury or bilateral nephrectomy. Kidney Internal. 2008;74(314):901909. doi:10.1038/ki.2008.314

10. Guo Zhi WX, Wang YX, Guohong LS.Rheb-mediated amelioration of insulin resistance and Von Willbrand factor antigen in the overweight. Int J Obes. 2016;17(12):723-725

11. Porreca ED, Febbo C, Fusco L, Moretta V, DiNisio M, Cuccurullo F. Soluble thrombomodulin and vascular adhesion molecule-1 are associated to leptin plasma levels in obese women. Atherosclerosis. 2004;172(1):175-180. doi:10.1016/j.atherosclerosis.2003.09.022 


\section{Publish your work in this journal}

Pathology and Laboratory Medicine International is a peer-reviewed, open access journal focusing on innovative basic research and translational research related to pathology or human disease. The journal includes original research, updates, case reports, reviews and commentaries on

Submit your manuscript here: https://www.dovepress.com/pathology-and-laboratory-medicine-international-journal current controversies. The manuscript management system is completely online and includes a very quick and fair peer-review system. Visit http://www.dovepress.com/testimonials.php to read real quotes from published authors. 